\title{
MONTAGEM DE UTOPIAS URBANAS COMO MODO DE PENSAR
}

\author{
Leo Name* \\ * Universidade Federal da Integração Latino-Americana, Curso de Arquitetura e Urbanismo, Programa \\ de Pós-graduação em Literatura Comparada, Programa de Pós-graduação Interdisciplinar em \\ Estudos Latino-americanos, Foz do Iguaçu, Paraná, Brasil. \\ CAÚLA, Adriana. Trilogia das utopias urbanas. Salvador: Edufba, 2019. 369 p.
}

Em 1996, enquanto frequentava uma disciplina de projeto de arquitetura de meu terceiro período na Faculdade de Arquitetura e Urbanismo da Universidade Federal do Rio de Janeiro (FAU-UFRJ), a professora respondeu às dificuldades de alunas e alunos a respeito da expressão gráfica convidando para vir em nosso auxílio uma estudante de alguns semestres à frente. Tímida, com muita paciência e o mais vistoso estojo de lápis aquareláveis e canetinhas que eu já tinha visto, ela nos explicou como colorir e como dar asas à imaginação para - por que não? - apresentar o projeto da disciplina com a linguagem dos quadrinhos. Era Adriana Caúla, com quem trabalhei, depois, em um escritório de arquitetura - quando ela terminava sua dissertação no Programa de Pós-graduação em Urbanismo (PROURB) da mesma universidade sobre cidades imaginárias nos quadrinhos e eu iniciara minha pesquisa de mestrado sobre a capital fluminense no cinema. Entre um e outro desenhos no AutoCAD, trocávamos impressões, textos e imagens desse universo midiático - intercâmbio que ainda conservamos. Mantive-me no Rio de Janeiro no doutorado, ela seguiu para Salvador, para o Programa de Pós-graduação em Arquitetura de Urbanismo da Faculdade de Arquitetura da Universidade Federal da Bahia (PPG-AU/FAUFBA): Trilogia das utopias urbanas (2008) foi seu trabalho relacionando quadrinhos, cinema e urbanismo à literatura utópica, vencedor do prêmio Capes na categoria de "teses” na área. Aqui resenho sua conversão em livro, lançado em dezembro de 2019 pela Edufba.

Parto da pessoalidade e da afetividade de meu relato porque não posso furtar-me da parcialidade na tarefa de comentar o trabalho de Caúla - atualmente 
docente na Escola de Arquitetura e Urbanismo da Universidade Federal Fluminense (EAU-UFF). Conheço-o esmiuçadamente porque somos amigos há duas décadas e temos visões de mundo e interesses acadêmicos semelhantes. Assumo essa posição e vejo-a como uma vantagem, inclusive porque minha releitura do texto - cujas marcas epistemológicas de seu tempo, mantidas na edição da Edufba, tentarei contextualizar - pôde ser complementada com o debate direto com a autora.

Na década de 2000, na qual Caúla escrevia sua tese, havia quantidade relevante de pesquisadoras e pesquisadores voltados aos debates - de clara origem anglófona - sobre "cinema e cidade" (CLARKE, 1997; SCHIEL; FITZMAURICE, 2001). Naquela produção brasileira em urbanismo e geografia, o comparatismo literário que fora revigorado ao final da década de 1970 por Edward Said ([1978] 2007) traduzia-se em cotejamento de imagens do cinema - em grande medida devido ao impacto da notória análise de David Harvey sobre Blade Runner e Asas do desejo em A condição pós-moderna ([1989] 1994). Teses e dissertações, como as de Maria Helena Costa (2000), Jorge Luís Barbosa (2002), Leo Name (2004) e Silvana Olivieri (2007), debruçavam-se sobre as dimensões espaciotemporais do cinema e sua relação com as culturas e os conflitos urbanos. Também o Laboratório Urbano - grupo de pesquisa do PPG-AU/FAUFBA no qual Caúla se inseriu, liderado por sua então orientadora Paola Jacques - centrava atenção em “corpografias”, microexperiências e espetacularizações urbanas (BRITTO; JACQUES, 2008; JACQUES; JEUDY, 2006). Ao mesmo tempo, a pesquisa coletiva "Cronologia do Pensamento Urbanístico" conduzida pelo mesmo grupo desde 2003, ainda em andamento e da qual Caúla fez parte - iniciava seus trabalhos sobre a circulação de ideias e a história intelectual do urbanismo.

O livro de Caúla divide-se em três partes não numeradas sequencialmente, chamadas de "blocos": Utopias (a), Utopografias (b) e Cartografias (c) - uma primeira leitura possível do termo trilogia presente no título do trabalho. No Bloco Utopias, a autora promove um debate teórico que se apoia em uma literatura bem distinta daquela utilizada nos trabalhos sobre cinema e cidade que lhe eram contemporâneos. Ao esmiuçar as definições de "utopia” - segundo Caúla, um vocábulo de significado e trajetória instáveis e cambiantes que desenha esquema de imaginação polissêmico e irônico -, ela aciona o teórico italiano Amedeo Bertolo, o historiador polonês Bronislaw Baczkö, o sociólogo húngaro Karl Manheim e o semiólogo francês Louis Marin, por exemplo. Ela dialoga, sobretudo, com Gilles Deleuze e Félix Guattari - muito em voga no tempo da escrita da tese -, mais particularmente com a ideia de que a filosofia consiste na criação de conceitos fundamentados num pensamento que desenvolve um espaço próprio como um campo sem limites; e por meio do qual se desloca destruindo estratificações e instituindo 
uma reflexão “desterritorializada”. Com base nisso, Caúla anuncia que a utopia é um modo de pensar voltado à crítica e que as utopias urbanas produzidas entre 1516 e 2007 - o enorme período que o trabalho abarca! - são "uma forma de discurso, uma forma de posicionamento, cada qual em relação a contextos, meios, campos e acontecimentos" (p. 16a). A autora as vê "como um fluxo, como um processo de pensamento e território livre" a que ela responde com sua obra, concebida como construção aberta de livre acesso e para um sem-número de interpretações para essas mesmas cidades.

Desde sua dissertação (CAÚLA, 2001), eram os quadrinhos (que unem imagem, texto e insinuação de tempo e movimento) e não os filmes (que recebiam muito mais atenção de pesquisadoras e pesquisadores da época), que estavam no centro do debate que ela realizava: somente depois Caúla agregou aos quadrinhos os filmes, relacionando-os também com o urbanismo e a literatura utópica. Na forma de escrita alfabética e desde a crônica irônica de Thomas More, de 1516, foi a literatura, diz-nos então Caúla no livro/tese, que instaurou o repertório principal das utopias, influenciando outros campos. Compreendidas como "invenções que tomam o urbano como ambiente/criação essencial” ou "críticas focadas em concepções espaciais” e "na invenção de cidades que não existem” (p. 44-45a), as utopias urbanas são analisadas na forma específica de escrita imagética dos outros três campos - quadrinhos, cinema e urbanismo, outra trilogia a remeter-se ao título.

Atenta ao fato de que a cultura ocidental "não estoca sua história apenas em palavras e textos, mas igualmente em imagens” (p. 47a), Caúla não os trabalha em oposição; afinal, quadrinhos, literatura e cinema partem, do mesmo modo que o urbanismo, da observação da cidade que capta embates, disputas e transformações, fazendo-a "imagem projetada" (p. 50a). Filmes, antes de se tornarem imagens em movimento, são estáticos storyboards; filmes e quadrinhos são textos quando ainda são roteiros; e, finalmente, o urbanismo produz tanto espaços como significados produzindo tanto textos quanto imagens. É por isso que, na “orelha” do livro, Jacques o apresenta como uma "pesquisa de cultura visual que reúne milhares de imagens que [...] criam novas conexões entre campos distintos e, assim, desestabilizam seus sentidos preestabelecidos”.

Que metodologia é possível acionar para dar conta de tantas imagens ao longo de quase quinhentos anos de imaginações urbanas e utópicas que constantemente se redefinem por diferentes campos e linguagens?

Caúla aponta dois tipos de movimentos nos discursos sobre as utopias urbanas: "atualizações encubadas" seriam os pequenos movimentos dentro de um mesmo campo ou linguagem (o urbanismo alimentando o próprio urbanismo, filmes se autorreferenciando, e assim por diante). Já as "atualizações por contami- 
nação" tratam dos grandes movimentos que perpassam vários campos. De modo a torná-los mais perceptíveis, a autora lança mão de sua mais potente criação: as "tipias urbanas". Nas suas modestas palavras, "tipia” seria simplesmente o "nome que se aplica ao material de composição criado nas utopias", ou o "elemento visual dinâmico componente das imagens das utopias” (p. 61a). O trabalho elenca dezoito tipias: pequenos quadrados em preto e branco - singelas, porém potentes sínteses visuais que permitem a Caúla demonstrar recorrências no longo rastro das utopias urbanas (Figura 1).

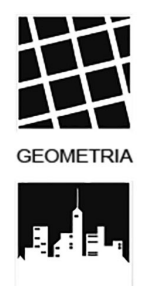

DIVERSA

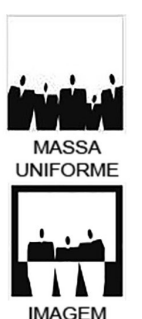

IMAGEM

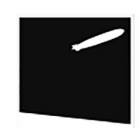

VOADORES

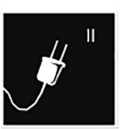

CONECTOR
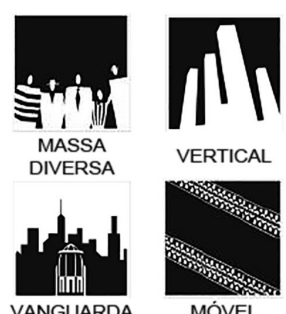

VERTICAL

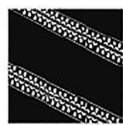

MÓVEL

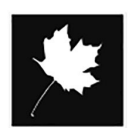

NATUREZA

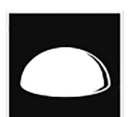

DOMO
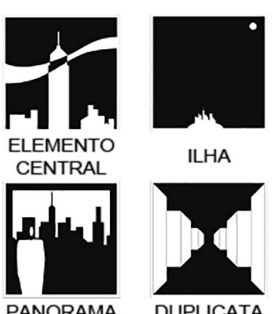

ILHA

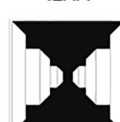

DUPLICATA

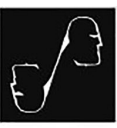

SER

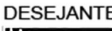

ime

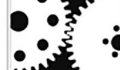

Figura 1. Tipias.

Fonte: Caúla (2019, p. 17a).

Ao longo do Bloco Utopografias e do Bloco Cartografias, as tipias são acompanhadas de pequenas definições e elencadas de distintas maneiras, visionando se definir e - na falta de melhor palavra - catalogar as utopias urbanas. O Bloco Utopografias dedica-se às atualizações encubadas, subdividindo-se em análises da literatura utópica (a Utopia de More, a Cidade do Sol de Campanella ou o Admirável mundo novo de Huxley, por exemplo), do urbanismo utópico (a Garden City de Howard, a Città Nuova de Sant'Elia, ou a Ville Radieuse de Le Corbusier) e das utopias nos quadrinhos (de Little Nemo in Slumberland, de Winsor McCay, a Terminal City, de Motter e Lark) e no cinema (de Metrópolis, de Fritz Lang, a Star Wars da franquia da Lucasfilm Limited). Nas margens das páginas, Caúla dispõe tipias acompanhadas de curtas explicações identificando a que elas se referem em cada cidade, criando um texto paralelo ao principal. E, ao final de cada grupamento (literatura, urbanismo, quadrinhos, cinema), há uma linha de tempo que informa quais tipias estão presentes em cada obra: "Geometria”, "Imagem”, “Conector”, "Vanguarda" e "Móvel” em Laranja mecânica, de Kubrick; ou "Massa uniforme", "Voador”, “Máquina”, “Diverso”, “Ser desejante” e "Panorama” na Matrix, de Lilly e Lana Wachowski, por exemplo.

O Bloco Cartografias é dedicado às atualizações por contaminação: parte-se de uma tipia em específico para apresentar seu trajeto entre diferentes obras e campos. Por exemplo: considerada a tipia "Voador", Caúla mostra que zepelins, 
balões ou aviões estão na Nova Atlântida de Bacon, na Ville Contemporaine de Le Corbusier, na Los Angeles de Ridley Scott, em Blade Runner, e no Flash Gordon, de Alex Raymond, por exemplo; considerada a tipia "Vertical", ganha relevo a onipresença dos arranha-céus, seja na Cité Industrialle de Tony Garnier, seja nas Cités Obscures, de Schuiten e Peeters, ou no filme The Thirteenth Floor, dirigido por Josef Rusnak. Finalizam esse bloco montagens, produzidas pela própria autora, que reúnem várias cidades utópicas da literatura, do urbanismo, dos quadrinhos e do cinema que apresentem uma mesma tipia (Figura 2).

\section{Nit}

\section{VERTICAL}

A tipia vertical é o elemento verticalizado na composição da utopia urbana.

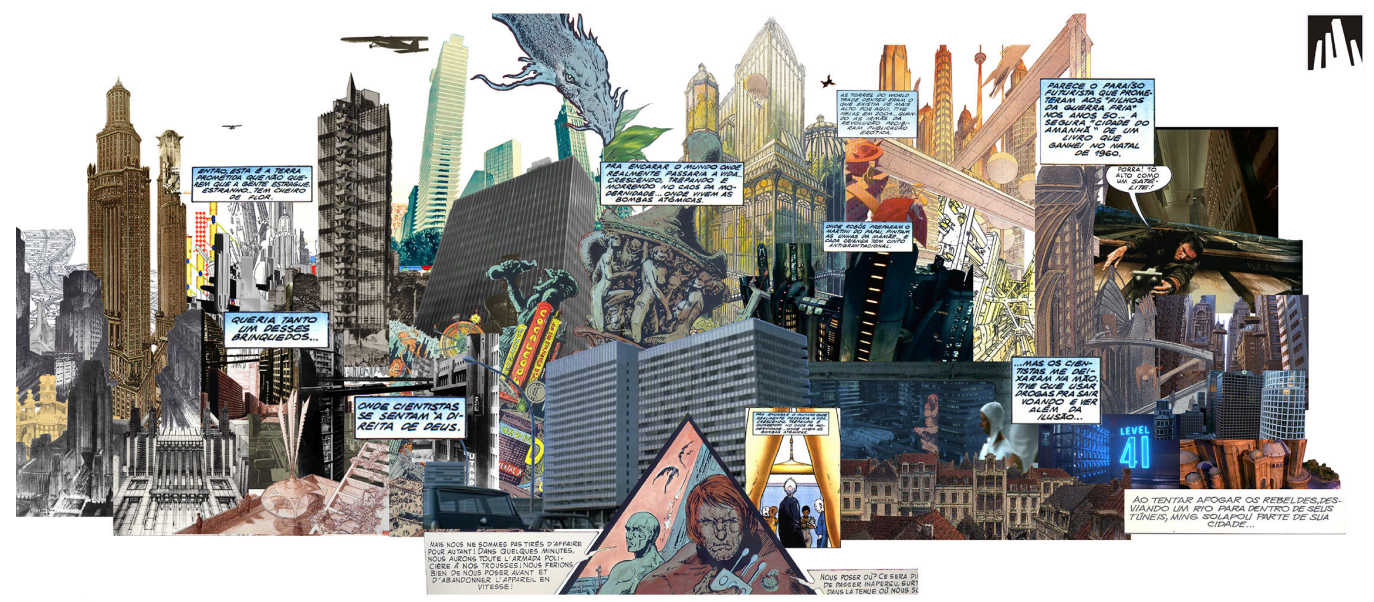

\section{VOADORES}

A tipia voadores, como o próprio nome já diz, évista e identificada nos elementos voadores das imagens das utopias urbanas. Sejam eles veículos, pessoas ou até cidades inteiras.

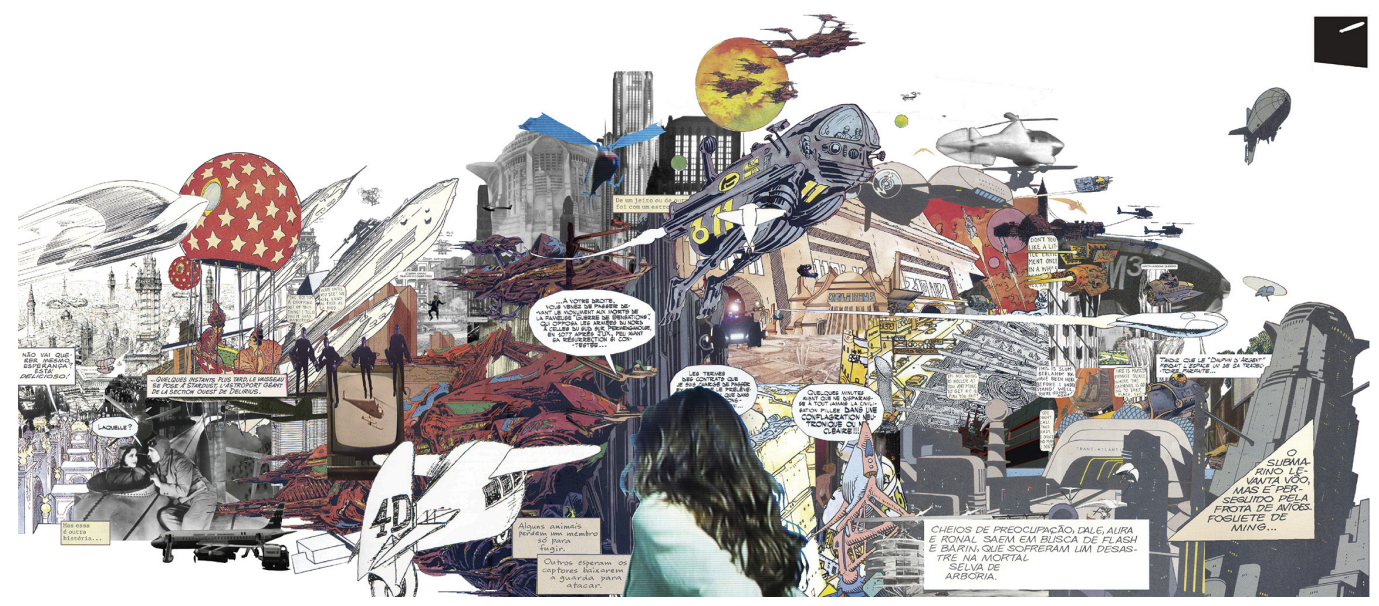

Figura 2. Vertical/Voadores.

Fonte: Caúla (2019, p. 51C). 
Retorno ao início do texto, sobre meu primeiro encontro com a autora, para reformular a pergunta que anuncia seu modo de pensar: por que não montar um livro/tese que misture diferentes linguagens e modos de ler? Trilogia das utopias urbanas é uma obra transdisciplinar e transmidiática, voltada à repetição na diacronia e compreensiva da complexidade da circulação de imagens na contemporaneidade. Embora jamais Caúla pudesse nos prover da análise de todas as utopias urbanas, impressiona o fato de ela ter reunido 100 cidades utópicas (25 na literatura, 25 feitas por urbanistas, 18 nos quadrinhos e $32 \mathrm{em}$ filmes). Sob o suporte das tipias, ela as descortina como "imagens-arquivo" - depositárias umas das outras e de significados correlacionáveis, com integridade hermenêutica e unidade icônica (BARRIENDOS, [2011] 2019) -, tornando a leitura do trabalho obrigatória e prazerosa.

Creio ser importante, contudo, também indicar algumas ressalvas.

As montagens ao final do último bloco do livro não existiam na tese de 2008. Foram criadas em razão dos direitos autorais que incidiriam sobre as incontáveis imagens que compunham o texto original. Tais composições oferecem uma bem-vinda síntese visual, mas foram ajustadas na edição à estreita dimensão horizontal de uma página: lamentavelmente, assim se perdem os muitos detalhes de seus esmerados desenhos em formato panorâmico. Outro problema: no que no livro se apresentam como três blocos de um mesmo volume (Utopias, Utopografias e Cartografias), na tese eram seis volumes encadernados em separado e dispostos em uma caixa cuidadosamente confeccionada por aquela que um dia tentou me ensinar a colorir. A mudança, significativa, responde ao controle de custos em uma editora universitária, o que é compreensível. No entanto, o formato originalmente proposto não era um capricho, mas um enunciado sobre as possibilidades de leitura aleatória, parcial e não sequencial que aquela montagem proporcionava - muitíssimo mais limitadas na brochura única.

No que diz respeito ao conteúdo, penso que a marca deleuziana da época do texto original e a adesão à formulação abstrata de desterritorialização fazem com que Trilogias das utopias urbanas pareça não perceber as geometrias de poder que desenham quaisquer formulações de ideias, utópicas ou não. Ao que parece se assume que, por terem circulado e ainda circularem demasiadamente, as imagens em análise não possuem lugar de enunciação. Ocorre, porém, que todas as 100 cidades utópicas do livro/tese foram desenvolvidas em poucos países centrais da Europa e nos Estados Unidos. Não creio que sua alta mobilidade as faça desprender-se da geopolítica do conhecimento que possibilita a maior circulação de determinadas imagens, ideias e conhecimentos - necessariamente situados - em detrimento de outros, inclusive atravessando o senso comum sobre o urbano e suas utopias. 
Outro ponto ignorado no trabalho é o fato de que Utopia foi escrito por Thomas More pouquíssimos anos após as primeiras viagens de "descobrimento": há quem veja no texto indicações de que a ilha se localiza próxima à América invadida por portugueses e espanhóis ou que seja ela própria (CAVE, 1991; EMERY, 2007). Assim, Utopia não exatamente apresentaria um bom lugar que é ao mesmo tempo lugar-nenhum, como indica sua etimologia, mas se desenharia com base na geografia assimétrica da circulação das ideias e no dualismo entre velhos e novos mundos que é a quintessência da modernidade. Em outras palavras, desdobrados de sua obra inaugural, o pensamento utópico em geral e as utopias urbanas em particular são legados do colonialismo e do imperialismo, mas por seu conteúdo crítico tornam-se passíveis de se converterem em narrativas sobre suas injustiças.

Também vale a pena comentar que, num trabalho que chega a contemplar os arroubos imaginativos de Rem Koolhaas, causa estranhamento não haver utopias urbanas do sul global, como aquelas do brasileiro Sérgio Bernardes - uma lacuna depois preenchida pela pesquisa pós-doutoral de Caúla, realizada entre 2011 e 2012, na UFF, que as teve como objeto. Do mesmo modo, na medida em que a autora assertivamente considera que cidades utópicas não se restringem a cidades do futuro, sente-se falta, no conjunto que ela abarca, de narrativas do passado que tratavam de seu presente, como Primer nueva corónica y buen gobierno (1615) - manuscrito de Felipe Guamán Poma de Ayala, cujas imagens de cidades, críticas ao colonialismo espanhol, conjugavam espacialidades cartesianas e incaicas.

Volto ao contexto acadêmico da escrita da tese que originou o livro. Levando em conta as pesquisas do Laboratório Urbano naqueles anos de 2000, o trabalho parece aberto a rumos diferentes, se percebido que, no lugar do corpo e da microexperiência, têm-se o panorama e certo sentido de totalidade. Veem-se igualmente, contudo, rotas de aproximação: por um lado, porque a torrente de imagens em análise, mesmo que dotadas de conteúdo crítico, não deixam de compor camadas de espetacularização urbana; por outro, porque auxilia na validação de que numa cronologia do pensamento urbanístico devam figurar ideias e imaginações de não urbanistas. Outrossim, o comparatismo entre literaturas, quadrinhos, urbanismos e filmes que projetam utopias urbanas confere à narrativa o papel de simultaneamente descrever e instituir cidades: nesse sentido, Trilogia das utopias urbanas antecipou um enunciado que adquiriria maior peso na produção do Laboratório Urbano somente na década seguinte (BRITTO; BECHLER; NAME, 2020). Parece ter antecipado, também, provavelmente absorvendo debates àquele momento mais difusos, a consideração de que toda montagem - como são a tese e o livro de Caúla - é um "modo de pensar" (JACQUES, 2018) tão potencializador de criatividades e liberdades quanto em 1996 foi sugerir montar uma prancha de projeto de arquitetura inspirando-se na linguagem dos quadrinhos. 


\section{Referências}

BARBOSA, J. L. As paisagens crepusculares da ficção científica. 2002. Tese (Doutorado em Geografia) - Universidade de São Paulo, São Paulo, 2002.

BARRIENDOS, J. A colonialidade do ver: rumo a um novo diálogo visual interepistêmico. Epistemologias do sul, v. 3, n. 1, p. 38-56, (2011) 2019.

BRITTO, F. D., BECHLER, J.; NAME, L. Editorial. Redobra, ano 6, n. 15, p. 7-15, 2020.

BRITTO, F. D.; JACQUES, P. B. Cenografias e corpografias urbanas: um diálogo sobre as relações entre corpo e cidade. Cadernos PPG-AU/UFBA, v. 7 (Paisagens do corpo), p. 79-86, 2008.

CAÚlA, A. Cidades imaginárias: utopia, urbanismo e quadrinhos. 2001. Dissertação (Mestrado em Urbanismo) - Universidade Federal do Rio de Janeiro, Rio de Janeiro, 2001.

. Trilogia das utopias urbanas. 2008. Tese (Doutorado em Arquitetura e Urbanismo) - Universidade Federal da Bahia, Salvador, 2008.

CAVE, A. A. Thomas More and the New World. Albion, v. 23, n. 2, p. 209-229, 1991.

CLARKE, D. B. (org.). The cinematic city. London: Routledge, 1997.

COSTA, M. H. B. V. Cities in motion: towards an understanding of the cinematic city. 2000. Tese (Doutorado em Mídia) - University of Sussex, Brighton, 2000.

EMERY, B. A utopia brasileira. Portuguese Cultural Studies, v. 1, n. 1, p. 10, 2014.

HARVEY, D. A condição pós-moderna. São Paulo: Loyola, 1994.

JACQUES, P. B. Pensar por montagens. In: JACQUES, P. B.; PEREIRA, M. S. (org.). Nebulosas do pensamento urbanístico. Salvador: Edufba, t. 1, 2018. p. 206-234.

JACQUES, P. B.; JEUDY, H. P. (org.). Corpos e cenários urbanos. Salvador: Edufba, 2006.

NAME, L. Rio de cinema - made in Brazil, made in everywhere. 2004. Dissertação (Mestrado em Geografia) - Universidade Federal do Rio de Janeiro, Rio de Janeiro, 2004.

OLIVIERI, S. Quando o cinema vira urbanismo. 2008. Dissertação (Mestrado em Arquitetura e Urbanismo) - Universidade Federal da Bahia, Salvador, 2008.

SAID, E. W. Orientalismo. São Paulo: Companhia das Letras, (1978) 2007.

SCHIEL, M.; FITZMAURICE, T. (org.). Cinema and the city. Oxford: Blackwell, 2001. 


\section{Leo Name}

É bacharel em Arquitetura e Urbanismo e mestre e doutor em Geografia pela Universidade Federal do Rio de Janeiro (UFRJ). Atualmente, é professor adjunto da Universidade Federal da Integração Latino-Americana (Unila), no Curso de Arquitetura e Urbanismo do Centro Interdisciplinar de Território, Arquitetura e Design, no Instituto Latino-americano de Território, Infraestrutura e Tecnologia (Ilatit). Na mesma instituição, é também docente no Programa de Pós-graduação em Literatura Comparada e no Programa de Pós-graduação Interdisciplinar em Estudos Latino-Americanos. É líder do grupo de pesquisa ¡DALE! - Decolonizar a América Latina e seus Espaços, com pesquisas embasadas no giro decolonial latino-americano e cadastrado desde 2016 no Diretório de Grupos de Pesquisa do CNPq.

Email: Ipmname@gmail.com

ORCID: 0000-0002-1963-1094

Submissão: 14 de agosto de 2020.

Aprovação: 6 de setembro de 2020 .

Como citar: NAME, L. Montagem de utopias urbanas como modo de pensar. Revista brasileira de estudos urbanos e regionais. v.22, E202031, 2020. DOI 10.22296/2317-1529. rbeur.202031

Artigo licenciado sob Licença Creative Commons CC BY-NC 4.o.

https://creativecommons.org/licenses/by-nc/4.o/deed.pt_BR 